\title{
Peran Penyuluh Pertanian dalam Pembinaan Kelompok Wanita Tani (KWT) \\ (Kasus Pengolahan Kacang Kace Canavalia pada KWT Karang Sari dan KWT Merta Sari di Desa Nyanglan, Kecamatan Banjarangkan, Kabupaten Klungkung)
}

\author{
NI PUTU WULAN SUWARNINGMAS, I DEWA PUTU OKA SUARDI, \\ I GEDE SETIAWAN ADI PUTRA
}

\author{
Program Studi Agribisnis, Fakultas Pertanian, Universitas Udayana \\ Jl. PB. Sudirman Denpasar 80323 \\ Email : wulansuwarningmas@yahoo.com \\ okasuardi@yahoo.com
}

\begin{abstract}
The Role of Agricultural Extension in the Development of Women Farmers Group (KWT), (A Case on Kace Canavalia Bean Processing on the KWT of Karang Sari and KWT of Merta Sari in the Village of Nyanglan, Sub-District of Banjarangkan, Regency of Klungkung
\end{abstract}

Agricultural extension is a non formal education conducted by farmers to change the behavior of farmers, so that farmers become more advanced. Effective communication can support the success of agricultural extension, more importantly is to change the attitude and behavior of agricultural communities so that they learn and want to apply the information provided by Agricultural Extension. The objective of the research was to identify the roles of agricultural extension officers in the promotion of Women Farmers Group, either their role as educator, information dissemination/innovator, facilitator, consultant, supervision, monitoring and evaluation. The research was conducted in the KWT of Karang Sari and Merta Sari, the location of the study was chosen by purposive sampling. Selection of respondents was by saturated sampling method in accordance with the number of members of KWT i.e. as many as 14 people, and by using descriptive qualitative analysis method, i.e. the research aimed to provide description and explanation of the variables studied. The findings of the research showed that the role of agricultural extension in the KWT guidance, especially in the processing of Canavalia bean at KWT Karang Sari and Merta Sari has been able to play well in carrying out their duties. Revenue of KWT member of respondent is still below the Minimum Wage of Regency / City (UMK), which is Rp. 1,839,750.00 per month. This means that the extension workers are expected to foster the group of women farmers in processing Canavalia bean to have a high selling value in order to create independence and creativity of farmers in innovating to develop processed Canavalia bean products.

Keywords: role, extension workers, Women Farmers Group, Processing of Kace Canavalia Beans 


\section{Pendahuluan}

\subsection{Latar Belakang}

Pembangunan pertanian di Negara Indonesia masih terkendala oleh banyak faktor yang menyebabkan sulitnya para petani untuk berkembang, dibutuhkan fasilitator yang dilakukan oleh pekerja pengembangan masyarakat antara lain sebagai orang yang mampu membantu masyarakat agar masyarakat mau berpartisipasi dalam kegiatan bertani, orang yang mampu mendengar, memahami aspirasi masyarakat, mampu memberikan dukungan, dan mampu memfasilitasi kepada masyarakat.

Orang yang melakukan penyuluhan adalah petugas penyuluh pertanian. Petugas penyuluh pertanian tersebut merupakan petugas yang memiliki kompetensi di bidang pertanian. Kemampuan komunikasi yang baik oleh petugas penyuluh pertanian juga sangat dibutuhkan sehingga materi yang disampaikan dapat diterima dengan baik oleh petani. Penyuluh pertanian merupakan suatu usaha atau upaya mengubah perilaku petani dan keluarganya agar mereka mengetahui dan mempunyai kemauan serta mampu memecahkan masalahnya sendiri dalam usaha atau kegiatankegiatan meningkatkan hasil usahanya dan tingkat kehidupannya. Tujuan penyuluhan tersebut untuk mengubah perilaku (pengetahuan, sikap, dan keterampilan) petani, sehingga petani menjadi semakin maju dan berkembang.

Pembinaan usahatani melalui kelompok tani tidak lain adalah sebagai upaya percepatan sasaran. Petani yang banyak jumlahnya dan tersebar di pedesaan yang luas, sehingga dalam pembinaan kelompok diharapkan timbulnya cakrawala dan wawasan kebersamaan memecahkan dan merubah citra usahatani sekarang menjadi usahatani masa depan yang cerah dan tetap tegar. Kegiatan pembangunan pertanian di Indonesia banyak ditekankan melalui pemberdayaan sumberdaya manusia, upaya ini dilakukan melalui kegiatan penyuluhan pertanian yang antara lain dilakukan melalui pendekatan kelompok.

\subsection{Manfaat Penelitian}

Penelitian ini diharapkan dapat memberikan kontribusi dan manfaat bagi berbagai pihak, sebagai berikut.

1. Pemerintah sebagai salah satu masukan dan informasi pendukung atau pelengkap bagi dinas terkait dan sebagai rujukan pengambilan sikap untuk memutuskan suatu kebijakan dalam mengembangkan sektor pertanian dalam pembinaan Kelompok Wanita Tani (KWT) khususnya dalam pengolahan kacang kace.

2. Penyuluh diharapkan dapat sebagai acuan dalam melaksanakan tugasnya pada masa yang akan datang.

3. Sebagai bahan informasi dan pertimbangan bagi para pengambil kebijakan dan pihak-pihak yang berkepentingan dengan masalah kelompok tani dalam rangka pembinaan dan pengembangan kelompok tani dipedesaan. 


\subsection{Tujuan}

1. Mengetahui peran penyuluh pertanian dalam pembinaan kelompok Wanita Tani dalam pengolahan kacang kace di Desa Nyanglan, Kecamatan Banjarangkan, Kabupaten Klungkung.

2. Mengetahui pendapatan KWT dalam pengolahan kacang kace di Desa Nyanglan, Kecamatan Banjarangkan, Kabupaten Klungkung.

\section{Metode Penelitian}

\subsection{Lokasi dan Waktu Penelitian}

Penelitian ini dilaksanakan pada Kelompok Wanita Tani yang berada di Desa Nyanglan, Kecamatan Banjarangkan, Kabupaten Klungkung, pada bulan Mei hingga November 2016. Pemilihan lokasi dilakukan secara sengaja berdasarkan pertimbangan yaitu (1) KWT Karang Sari dan KWT Merta Sari di Desa Nyanglan, Kecamatan Banjarangkan, Kabupaten Klungkung merupakan kelompok tani binaan Dinas Pertanian Perkebunan dan Kehutanan Kabupaten Klungkung yang masih menjalankan program home industry dan (2) KWT Karang Sari dan KWT Merta Sari di Desa Nyanglan Kecamatan Banjarangkan, Kabupaten Klungkung ini merupakan Kelompok Wanita Tani yang aktif dalam proses pengolahan kacang kace dan selalu menghasilkan produk olahan kacang yang baik dan memiliki kualitas yang tinggi sehingga sampai menembus pasaran dan memiliki nilai jual yang tinggi.

\subsection{Jenis dan Sumber Data}

Data yang dikumpulkan dalam penelitian ini adalah data kuantitatif dan data kualitatif, sedangkan sumber data terdiri dari data primer dan data sekunder.

\subsection{Pengumpulan Data}

Metode yang digunakan dalam mengumpulkan data yaitu teknik wawancara, wawancara mendalam, dan dokumentasi.

\subsection{Populasi, Responden, dan Informan Kunci}

Populasi dalam penelitian ini adalah seluruh anggota Kelompok Wanita Tani Karang Sari dan Merta Sari di Desa Nyanglan, Kecamatan Banjarangkan, Kabupaten Klungkung yang berjumlah 14 orang. Pengambilan responden menggunakan metode sampling jenuh dimana penetapan semua populasi ditetapkan sebagai responden.

\subsection{Konsep Variabel, Indikator, Parameter, dan Skala Pengukuran}

Konsep variabel penelitian ini memiliki beberapa indikator (edukasi, diseminasi informasi/inovasi, fasilitasi, konsultasi, supervisi, monitoring, dan evaluasi) yang kemudian diukur dengan parameter tertentu yang dapat menunjukan peran penyuluh pertanian dalam pembinaan Kelompok Wanita Tani. 


\subsection{Analisis Data}

Analisis data merupakan proses mencari dan menyusun serta sistematis data yang diperoleh dari hasil wawancara, kuesioner, observasi, dan dokumentasi dengan menggunakan metode analisis deskriptif kualitatif (sugiyono, 2010). Jumlah variabel pada penelitian ini adalah 23 variabel dan terdiri dari tujuh indikator. Indikatorindikator tersebut diuraikan dalam bentuk pernyataan positif atau negatif, kemudian diberikan skor berdasarkan tanggapan responden terhadap pernyataan tersebut.

\section{Hasil dan Pembahasan}

\subsection{Peran Penyuluh Pertanian dalam Pembinaan Kelompok Wanita Tani (KWT)}

Peran Penyuluh Pertanian dalam Pembinaan Kelompok Wanita Tani (KWT) dalam pengolahan kacang kace pada KWT Karang Sari dan KWT Merta Sari. Mengetahui peranan penyuluhan tersebut digunakan beberapa indikator yaitu, peran penyuluh pertanian sebagai edukator, peran penyuluh pertanian sebagai diseminasi informasi/inovator, peran penyuluh pertanian sebagai fasilitator, peran penyuluh pertanian sebagai konsultan, peran penyuluh pertanian sebagai supervisior, peran penyuluh pertanian sebagai monitoring, dan peran penyuluh pertanian sebagai evaluator. Hasil penelitian menunjukan bahwa peran penyuluh pertanian termasuk kategori baik dengan pencapaian skor 3,90 dan pencapaian skor untuk masingmasing indikator seperti terlihat pada Tabel 1.

Tabel 1.

Peran Penyuluh Pertanian dalam Pembinaan Kelompok Wanita Tani (KWT) dalam Pengolahan Kacang Kace

\begin{tabular}{cccc}
\hline No & Indikator & Pencapaian skor & Kategori \\
\hline 1 & Edukasi & 3,96 & Baik \\
2 & Diseminasi Informasi/Inovasi & 4,02 & Baik \\
3 & Fasilitasi & 4,11 & Baik \\
4 & Konsultasi & 4,04 & Baik \\
5 & Supervisi & 4,17 & Baik \\
6 & Monitoring & 3,39 & Baik \\
7 & Evaluasi & 3,64 & Baik \\
\hline & Peran Penyuluh & 3,90 & Baik \\
\hline
\end{tabular}

1. Peran penyuluh pertanian sebagai edukator

Edukasi, yaitu untuk memfasilitasi proses belajar yang dilakukan oleh para penerima manfaat penyuluhan (beneficiaries) atau stakeholders pembangunan yang lainnya. Berdasarkan tabel 1, peran penyuluh pertanian sebagai edukator termasuk kategori baik dengan pencapaian skor 3,96. Hal ini menunjukkan bahwa penyuluh mampu berperan dengan baik sebagai edukator, yang ditunjukkan oleh kemampuan menjelaskan mengenai proses pengolahan kacang kace, kemampuan menjelaskan 
mengenai proses pengemasan kacang kace, dan kemampuan menjelaskan mengenai proses pemasaran kacang kace.

2. Peran penyuluh pertanian sebagai diseminasi informasi/inovator

Diseminasi informasi/inovasi, yaitu penyebaran informasi/inovasi dari pihak luar. Berdasarkan tabel 1 , peran penyuluh pertanian sebagai diseminasi informasi/inovator termasuk kategori baik dengan pencapaian skor 4,02. Hal ini menunjukan bahwa penyuluh mampu berperan dengan baik sebagai diseminasi informasi/inovator yang ditunjukkan oleh kemampuan dalam memberikan informasi mengenai proses pengolahan kacang kace, kemampuan dalam memberikan informasi mengenai cara pengemasan kacang kace, dan kemampuan dalam memberikan informasi mengenai proses pemasaran kacang kace.

\section{Peran penyuluh pertanian sebagai fasilitator}

Fasilitasi atau pendampingan, yang lebih bersifat melayani kebutuhankebutuhan yang dirasakan oleh klien-nya. Berdasarkan tabel 1, peran penyuluh pertanian sebagai fasilitator termasuk kategori baik dengan pencapaian skor 4,11. penyuluh mampu berperan dengan baik sebagai fasilitator dilihat dari segi memfasilitasi KWT dalam memasarkan produk olahan kacang kace, memfasilitasi KWT dalam hal peminjaman modal, memfasilitasi KWT dalam ketersediaan media alat bantu komunikasi, dan memberikan kesempatan berdiskusi dan bertatap muka.

\section{Peran penyuluh pertanian sebagai konsultan}

Konsultasi, yaitu membantu memcahkan masalah atau sekedar memberikan alternatif-alternatif pemecahan masalah. Berdasarkan tabel 1, peran penyuluh pertanian sebagai konsultan termasuk kedalam kategori baik dengan pencapaian skor 4,04. Hal ini menunjukan bahwa penyuluh mampu berperan dengan baik sebagai konsultan, yang ditunjukkan oleh kemampuan penyuluh dalam memberikan masukan serta saran mengenai proses pengolahan kacang kace, kemampuan penyuluh dalam memberikan masukan serta saran mengenai proses pengemasan kacang kace, dan kemampuan penyuluh dalam memberikan masukan serta saran mengenai proses pemasaran kacang kace.

\section{Peran penyuluh pertanian sebagai supervisor}

Supervisi atau pembinaan, yaitu upaya untuk bersama-sama client melakukan penilaian (self assesment), untuk kemudian memberikan saran alternatif perbaikan atau pemecahan masalah yang dihadapi. Berdasarkan tabel 1, peran penyuluh pertanian sebagai supervisor termasuk kedalam kategori baik dengan pencapaian skor 4,17. Hal ini menunjukan bahwa penyuluh mampu berperan dengan baik sebagai supervisor, dilihat dari segi memberikan penjelasan teknis tentang proses pengolahan kacang kace, memberikan penjelasan teknis tentang proses pengemasan kacang kace, dan memberikan penjelasan teknis tentang proses pemasaran kacang kace. 
6. Peran penyuluh pertanian sebagai monitoring

Monitoring, yaitu aktifitas yang ditunjukkan untuk memberikan informasi tentang sebab dan akibat dari suatu kebijakan yang sedang dilaksanakan. Berdasarkan tabel 1, peran penyuluh pertanian sebagai monitoring termasuk kategori baik dengan pencapaian skor 3,39. Hal ini menunjukan bahwa penyuluh mampu berperan dengan baik sebagai monitoring dilihat dari segi kinerja kelompok wanita tani, proses pengolahan kacang kace, kualitas pengemasan kacang kace, menilai tingkat pemasaran dari produksi kacang kace.

\section{Peran penyuluh pertanian sebagai evaluator}

Evaluasi, yaitu kegiatan pengukuran dan penilaian yang dapat dilakukan pada sebelum (formatif), selama (on-going, pemantauan) dan setelah kegiatan selesai dilakukan (sumatif, ex-post). Berdasarkan tabel 1, peran penyuluh pertanian sebagai evaluator termasuk kategori baik dengan pencapaian skor 3,64. Hal ini menunjukan bahwa penyuluh mampu berperan dengan baik sebagai evaluator yang ditunjukan oleh melakukan evaluasi tentang pengolahan kacang kace, melakukan evaluasi tentang pengemasan kacang kace, dan melakukan evaluasi tentang pemasaran kacang kace.

\subsection{Tingkat Pendapatan Pengolahan Kacang Kace pada Kelompok Wanita Tani (KWT)}

Kelompok Wanita Tani Karang Sari dan Merta Sari dalam sehari memproduksi 150 kg olahan kacang kace. Hasil olahan dari kacang Kace di KWT Karang Sari dan KWT Merta Sari dipasarkan ke Pasar Sukawati, Pasar Guwang, Pasar Klungkung, dan pengepul yang memiliki harga jual sebesar Rp 32.000,- per-Kg dan bahan mentah kacang kace atau koro dengan harga jual sebesar Rp 11.000,- per-Kg. Pendapatan yang diperoleh oleh KWT Karang Sari dan KWT Merta Sari dari hasil penjualan kacang kace kurang lebih sebesar Rp 4.800.000,00 per hari dan angka tersebut tidak bisa dipastikan, karena dalam setiap hari produksi kacang kace tidak menentu karena KWT memproduksi kacang sesuai dengan pesanan.

Pendapatan anggota KWT memberikan kontribusi yang berarti bagi pendapatan keluarga anggota. Hasil penelitian menunjukan bahwa sebagian besar pendapatan anggota KWT masih di bawah Upah Minimum Kabupaten/Kota (UMK), yaitu Rp 1.839.750,00 per bulan. Pendapatan yang diterima oleh anggota KWT responden adalah berasal dari upah tenaga kerja pada masing-masing usaha kacang kapri/asin, dan kacang kace. Adapun upah tenaga kerja per-hari adalah sebesar Rp $50.000,00$, dalam Satu bulan hari kerja rata-rata selama 20 hari, sehingga dalam satu bulan menerima upah kerja sebesar Rp 1.000.000,00. 


\section{Simpulan dan Saran}

\subsection{Simpulan}

Berdasarkan hasil penelitian disimpulkan sebagai berikut.

1. Penyuluh Pertanian mampu berperan dengan baik membinaan Kelompok Wanita Tani dalam pengolahan kacang kace di Desa Nyanglan, Kecamatan Banjarangkan, Kabupaten Klungkung, namun dalam kegiatannya mengalami hambatan-hambatan dalam proses pengolahan kacang kace, proses pengemasan kacang kace, dan proses pemasaran kacang kace.

2. Pendapatan yang diperoleh oleh KWT Karang Sari dan KWT Merta Sari dari hasil penjualan kacang kace kurang lebih yakni sebesar Rp 4.800.000,00 untuk setiap pesanan yang diterima.

\subsection{Saran}

Adapun saran yang dapat disimpilkan yakni.

1. Kelompok Wanita Tani perlu meningkatkan kualitas produk olahannya, sehingga dalam penjualan bisa bersaing di pasaran dengan produk lain sehingga dapat meningkatkan nilai jual dan pada akhirnya bisa meningkatkan pendapatan baik kelompok maupun perorangan.

2. Kelompok Wanita Tani Karang Sari dan Merta sari juga perlu memperluas jaringan dalam mendistribusikan hasil olahan kacang kace, dengan kemajuan teknologi yang sangat pesat petani dapat memanfaatkan media sosial yang sudah ada saat ini dalam mempromosikan hasil olahan kacang kace mereka agar lebih dikenal oleh masyarakat luas hingga sampai ke mancanegara.

3. Penyuluh Pertanian agar membina KWT untuk berinovasi mengembangkan produk olahan kacang kace guna menciptakan kreatifitas dan kemandirian anggota KWT dalam pengolahan kacang kace agar hasil olahan kacang kace lebih di kenal di lingkungan masyarakat.

\section{Ucapan Terimakasih}

Terimakasih kepada Bapak Wayan Wiyasa selaku PPL di Desa Nyanglan, Kecamatan Banjarangkan, Kabupaten Klungkung yang telah membantu peneliti dalam pencarian data penelitian, dan Ibu Made Artini selaku Kepala Bidang Pengembangan Sarana dan Prasarana di Dinas Pertanian Perkebunan dan Kehutanan Kabupaten Klungkung yang telah memberikan izin penelitian, serta kepada seluruh pihak yang telah memberikan pengarahan bimbingan dan juga dukungan dalam penyelesaian penelitian dan penulisan e-jurnal ini. Semoga penelitian ini dapat berguna dan dimanfaatkan sebagaimana mestinya.

\section{Daftar Pustaka}

Astiti, N.W.Sri. 2006. Curahan Tenaga Kerja Perempuan pada Usahatani Padi di Subak Guama Kabupaten Tabanan dalam Kembang Rampai Perempuan 
Bali. Hal. 85. Diedit oleh Luh Aryani, Nyoman Suparwa dan Sudarta. Kerjasama Biro BKPP Setda Bali dan Pusat Studi Wanita UNUD, Denpasar. Hadisapoetro. S. 1970. Pembangunan Pertanian. Yogyakarta. Fakultas Pertanian UGM.

Mardikanto, T. 1993. Penyuluhan Pembangunan Pertanian. Sebelas Maret University Press. Surakarta.

Mardikanto, T. 2002. Catatan Kecil Untuk Pedoman Pelaksanaan Penyuluhan Pertanian. Disampaikan Dalam Diskusi Draft Pedoman Penyuluhan Pertanian di Hotel Salak, Nopember 2002.

Mosher, A.t. 1996. Menggerakan Dan Membangun Pertanian, Syarat-Syarat Mutlat Pembangunan Dan Modernisasi, C.V. Yasaguna. Jakarta.

Padmowihardjo, Soedijanto. 1999. Media Penyuluhan Pertanian. Universitas Terbuka, Jakarta. (Materi Pokok LUHT 4330/3SKS/modul 1-9).

Slamet, M. (ed). 2000 Memantapkan Posisi dan Meningkatkan Peran Penyuluh Pembangunan Dalam Pembangunan. Disampaikan dalam Seminar Pemberdayaan Sumberdaya Manusia Menuju Terwujudnya Masyarakat Madani di Bogor, 25-26 September 2000.

Sugiyono, 2010. Metode penelitian Bisnis. Bandung: Penerbit Alfabeta.

Van den Ban, A.W dan H.S Hawkins. 1999. Penyuluhan Pertanian. Kanisius. Yogyakarta.

Windia, W. P. 2006. Gugurnya Hak Atas Warisan Menurut Hukum Adat Balidalam Kembang Rampai Perempuan Bali. Hal 154. Diedit oleh Luh Aryani, Nyoman Suparwa dan Sudantra. Kerja sama Biro BKPP Setda Bali dan Pusat Studi Wanita UNUD, Denpasar. 